\title{
Predictive Value of Hormonal Evaluation Before Prostate Needle Biopsy on Prostate Cancer T Stage and Prognosis
}

\author{
(1) Serdar Çelik MD ${ }^{1,2}$, (1) Ozan Bozkurt MD³, (1) Hüseyin Alperen Yıldız MD³, (1) Ömer Demir MD³, (1) Burçin Tuna MD4, \\ (D) Kutsal Yörükoğlu MD, (D Güven Aslan MD³ \\ 'University of Health Sciences, Bozyaka Training and Research Hospital, Clinic of Urology, lzmir, Turkey \\ ${ }^{2}$ Dokuz Eylül University Institute of Oncology, Department of Basic Oncology, Izmir, Turkey \\ ${ }^{3}$ Dokuz Eylül University Faculty of Medicine, Department of Urology, Izmir, Turkey \\ ${ }^{4}$ Dokuz Eylül University Faculty of Medicine, Department of Patology, Izmir, Turkey
}

\begin{abstract}
Objective: In this study we evaluated the hormone data before prostate needle biopsy (PNB) in patients who underwent retropubic radical prostatectomy (RRP) due to prostate adenocarcinoma (PCa). Correlations between the patients' RRP pathology results, recurrence-free survival (RFS), and hormone data were investigated.

Materials and Methods: Patients were evaluated in two groups according to RRP pathologic T stage: T2 (group 1) and T3 (group 2). Then patients were assessed in two groups based on total testosterone (TTE) values: $>300 \mathrm{ng} / \mathrm{dL}$ and $<300 \mathrm{ng} / \mathrm{dL}$. The preoperative data, hormone data, RRP pathologic data, and biochemical recurrence and RFS results were compared between these groups.

Results: A total of 81 patients were evaluated. The mean follow-up time was 37.7 months. Mean recurrence free survival (RFS) among all patients was $94.2 \pm 7$ months. In multivariate analysis of the preoperative data, $T \mathrm{TE} /$ prostate volume $(\mathrm{p}=0.015)$ and $\mathrm{PNB}$ tumor percentage $(\mathrm{p}=0.004)$ were significantly higher in group $2(n=32)$ compared to group $1(n=49)$. In the postoperative data, RRP pathology Gleason score (GS) ( $p=0.015)$ and tumor volume ( $p=0.02)$ were significantly higher in group 2 . RFS was $99.2 \pm 5.8$ months in group 1 and $77 \pm 12.1$ months in group 2 ( $p=0.02)$. When patients were assessed according to TTE levels, of the pre- and postoperative data only RRP pathology T stage, GS, and lymph node positivity were significantly higher in the TTE $<300 \mathrm{ng} / \mathrm{dL}$ group $(\mathrm{n}=30)$ compared to the TTE $>300 \mathrm{ng} / \mathrm{dL}$ group $(\mathrm{n}=51)$. The biochemical recurrence rates and RFS times ( $87.7 \pm 13.8$ months and $91.3 \pm 6.4$ months, respectively) were similar between the groups $(\mathrm{p}=0.571)$.

Conclusion: We demonstrated a correlation between locally invasive PCa and low TTE measured before PNB and low TTE density. In particular, TTE values $<300 \mathrm{ng} / \mathrm{dL}$ were associated with high pathologic T stage, GS, and lymph node positivity.
\end{abstract}

Keywords: Prostate needle biopsy, testosterone, prostate cancer, recurrence-free survival, hormonal evaluation

\section{Introduction}

Several preoperative factors have been investigated and risk classifications have been defined in order to predict locally invasive disease and gain insight about the prognosis of prostate adenocarcinoma ( $\mathrm{PCa}$ ). The most important of these is the D'Amico risk classification, which includes prostatespecific antigen (PSA), prostate needle biopsy (PNB), Gleason score (GS), and clinical stage $(1,2,3)$. However, some argue that this classification is inadequate. Of the other parameters studied, findings of perineural invasion (PNI), number of positive biopsy cores, and tumor percentage in PNB are also important $(4,5)$. Numerous studies have investigated the association between locally advanced disease and pre-treatment levels of free testosterone (fTE), estradiol (EST), follicle-stimulating hormone (FSH), luteinizing hormone (LH), and especially total testosterone (TTE) $(4,6,7,8,9,10)$

Therefore, in this study we evaluated patients who underwent 
retropubic radical prostatectomy (RRP) in our clinic due to PCa and had pre-PNB hormone data. We investigated the relationship between the patients' hormone data and their RRP pathology results and survival outcomes.

\section{Materials and Methods}

Patients who underwent RRP in our clinic between 2005 and 2015 and had complete PNB and RRP pathology records were retrospectively screened. Of these, patients whose records included pre-PNB hormone tests were included in the study. The patients were evaluated in terms of age, PSA, free PSA, PSA density (PSAd), PNB pathology results (GS, number of positive biopsy cores, tumor percentage, and PNI positivity), prostate volume (PV), clinical stage, RRP pathology results (pathologic T stage, GS, tertiary Gleason pattern, tumor volume, surgical margin positivity, and lymph node positivity), biochemical recurrence rates, and recurrence-free survival time. Analysis of hormone data included TTE, fTE, $\mathrm{LH}, \mathrm{FSH}$, and EST values. PSAd (PSA/PV), fPSA/PSA, TTE/PV, fTE/TTE, TTE/LH, FSH/LH, TTE/FSH, and TTE/EST ratios were calculated from the available data.

Patients were evaluated in two groups based on RRP pathology T stage. Group 1 comprised patients with pathological T2 PCa and group 2 comprised those with pathological T3 PCa. Group 2 was further subdivided into pathological T3a (pT3a) and pathological T3b (pT3b) for separate analysis. All data were compared between group 1 and group 2. In a second analysis, patients were divided into two groups based on TTE value $(>300 \mathrm{ng} / \mathrm{dL}$ and $<300 \mathrm{ng} / \mathrm{dL}$ ). The groups were compared in terms of preoperative data, hormone data, RRP pathology results, biochemical recurrence, and survival rates.

\section{Statistical Analysis}

The Mann-Whitney $\mathrm{U}$ test and Pearson's $\chi^{2}$ test were used both for comparisons between groups 1 and 2 and between the TTE $<300 \mathrm{ng} / \mathrm{dL}$ and $<300 \mathrm{ng} / \mathrm{dL}$ groups. Significant parameters were then used in multivariate binary logistic regression analysis. Recurrence-free survival times were assessed using the KaplanMeier survival analysis. The Statistical Package for the Social Sciences (SPSS version 20.0; SPSS, Chicago, IL, USA) was used for statistical analyses. The data are expressed as mean and standard deviation and statistical analysis is based on median values. Values with a $p$ value of $<0.05$ were considered significant.

\section{Results}

Of the 381 patients whose PNB and RRP pathology results were screened, 81 with available hormone test results were retrospectively evaluated. Their mean age was 62.8 (48-76.5) years and the mean follow-up period was 37.7 months. Forty-nine of the patients were in group 1 and 32 were in group 2 . In group 2, 24 patients were pT3a, 8 were pT3b. Biochemical recurrence was detected in a total of 13 patients. Patient data from groups 1 and 2 are shown in Table 1. Preoperatively, group 2 had higher age, PSA, PNB GS, PNI positivity, number of positive biopsy cores, and tumor percentage values, and lower TTE level and TTE/ PV ratio compared to group $1(p<0.05)$. In the postoperative data, group 2 also showed higher values for RRP pathology GS, tertiary Gleason pattern, tumor volume, surgical margin positivity, lymph node positivity, and biochemical recurrence rates $(p<0.05)$. In multivariate analysis of the preoperative data, only TTE/PV $(p=0.015)$ and PNB tumor percentage $(p=0.004)$ were significantly higher in group 2 . Postoperatively, only the RRP pathology GS $(p=0.015)$ and tumor volume $(p=0.02)$ were significantly higher in group 2 . The mean recurrence-free survival time among all patients was $94.2 \pm 7$ months. By group, recurrence-free survival time was $99.2 \pm 5.8$ months in group 1 and $77 \pm 12.1$ months in group $2(p=0.02)$.

In the second analysis, patient data were compared between the TTE $>300 \mathrm{ng} / \mathrm{dL}$ and $<300 \mathrm{ng} / \mathrm{dL}$ groups. Data distributions and the results of statistical analyses are presented in Tables 2 and 3. There were 30 patients in the TTE $<300 \mathrm{ng} / \mathrm{dL}$ group and 51 patients in the TTE $>300 \mathrm{ng} / \mathrm{dL}$ group. There were no significant differences between the groups other than preoperative TTE level (Table 2). In the postoperative data, RRP pathology T stage, GS, and lymph node positivity were higher in the TTE $<300 \mathrm{ng} / \mathrm{dL}$ group (Table 3). Biochemical recurrence rates and recurrence-free survival time were similar between the groups. In the multivariate analysis, postoperative RRP pathology T stage and GS were lower in the TTE $<300 \mathrm{ng} /$ $\mathrm{dL}$ group, but the difference was not statistically significant $(p=0.054$ and $p=0.052$, respectively). Recurrence-free survival time was $87.7 \pm 13.8$ months in the $T \mathrm{TE}<300 \mathrm{ng} / \mathrm{dL}$ group and $91.3 \pm 6.4$ months in the TTE $>300 \mathrm{ng} / \mathrm{dL}$ group $(p=0.571)$.

\section{Discussion}

Although the link between TTE level and PCa has been recognized since Huggins et al.'s (11) 1941 study, it has recently gained a different dimension. Several recent studies have supported a negative correlation between low TTE level and PCa $(12,13,14)$. One hypothesis regarding the pathophysiology of this relation suggests that the tumor reduces TTE level by causing inhibition of the hypothalamicpituitary-adrenal axis $(15,16)$. In addition, it has been reported that TTE levels normalize in these patients after RRP. However, another hypothesis is that low TTE level causes a mutation in the development of PCa cells and leads to the development of cancer cells that are androgen-insensitive and more aggressive (17). In light of these possible mechanisms, the relationship between PCa and TTE is worthy of further elucidation. In a related study we conducted recently, we evaluated patients with similar PSA, clinical stage, and PNB GS data within the D'Amico risk groups. In that study, we found that TTE levels decreased as risk group increased (TTE levels were $368 \mathrm{ng} / \mathrm{dL}$, $311 \mathrm{ng} / \mathrm{dL}$, and $221.5 \mathrm{ng} / \mathrm{dL}$ in low-risk, moderate-risk, and high-risk $P C a$, respectively; $p=0.033$ ) (10). Low TTE level has been associated with high T stage and GS after RRP, especially in studies assessing the low-risk group $(18,19)$.

When patients were evaluated according to pathological T stage, the mean TTE value was found to be $4.33 \mathrm{ng} / \mathrm{mL}$ in T2 patients and $3.44 \mathrm{ng} / \mathrm{mL}$ in T3 patients (20). Many studies have used a TTE threshold value of $3 \mathrm{ng} / \mathrm{mL}(300 \mathrm{ng} / \mathrm{dL})$, and patients with $T \mathrm{TE}<3$ $\mathrm{ng} / \mathrm{mL}$ were shown to have higher RRP pathology GS and higher rate of T3 cancer (21). In another study, the pre-PNB TTE levels of 681 patients were investigated and low TTE ( $<300 \mathrm{ng} / \mathrm{dL})$ level was associated with high-risk PCa (22). In the present study, TTE and especially TTE/PV (TTE density) were lower in patients with pathological T3 PCa $(p<0.05)$. Similar to previous studies, when the TTE threshold was defined as $300 \mathrm{ng} / \mathrm{dL}$, there was significantly 
Çelik et al.

Effect of Hormonal Data on Prostate Cancer

\begin{tabular}{|c|c|c|c|c|}
\hline Mean \pm SD & pT2 (group 1) $(n=49)$ & pT3 (group 2) (n=32) & $p$ value & MV p value \\
\hline Age (years) & $61.2 \pm 5.7$ & $65.3 \pm 5.9$ & 0.004 & - \\
\hline PSA (ng/mL) & $6.9 \pm 4.6$ & $10.4 \pm 7.4$ & 0.01 & 0.744 \\
\hline fPSA $(n g / m L)$ & $1.2 \pm 1.3$ & $1 \pm 0.4$ & 0.653 & - \\
\hline $\mathrm{PV}(\mathrm{cc})$ & $44.3 \pm 26.4$ & $41.7 \pm 9.8$ & 0.591 & - \\
\hline PSA/PV (PSA density) (cc/ng/mL) & $0.19 \pm 0.16$ & $0.27 \pm 0.21$ & 0.051 & - \\
\hline fPSA/PSA ratio & $0.18 \pm 0.11$ & $0.14 \pm 0.1$ & 0.288 & - \\
\hline TTE (ng/dL) & $399.9 \pm 152.1$ & $303.2 \pm 148.8$ & 0.006 & 0.351 \\
\hline fTE $(n g / d L)(n=73)$ & $10.5 \pm 4.3(n=41)$ & $12.1 \pm 16.5(n=32)$ & 0.054 & - \\
\hline TTE/PV (TTE density) (ng/dL/cc) & $12.3 \pm 9.2$ & $7.8 \pm 4.1$ & 0.01 & 0.015 \\
\hline fTE/TTE ratio $(n=73)$ & $0.03 \pm 0.01(n=41)$ & $0.05 \pm 0.08(n=32)$ & 0.687 & - \\
\hline LH (IU/L) (n=57) & $4.3 \pm 1.8(n=25)$ & $5.7 \pm 2.8(n=32)$ & 0.113 & - \\
\hline FSH (IU/L) (n=59) & $8.7 \pm 9.2(n=25)$ & $10.2 \pm 8.1(n=34)$ & 0.384 & - \\
\hline EST $(p g / m L)(n=57)$ & $31.5 \pm 13.5(n=25)$ & $31.6 \pm 15.2(n=32)$ & 0.912 & - \\
\hline TTE/LH ratio $(n=57)$ & $90.2 \pm 48.6(n=25)$ & $67.2 \pm 66.9(n=32)$ & 0.063 & - \\
\hline FSH/LH ratio $(n=57)$ & $1.9 \pm 1.2(n=25)$ & $1.7 \pm 1(n=32)$ & 0.542 & - \\
\hline TTE/FSH ratio $(n=59)$ & $64 \pm 52.7(n=25)$ & $41 \pm 31.2(n=34)$ & 0.122 & - \\
\hline PNB GS & $6.5 \pm 0.6$ & $6.9 \pm 0.7$ & 0.007 & 0.431 \\
\hline PNB PNI, n (\%) & $8(16)$ & $17(53)$ & $<0.001$ & 0.213 \\
\hline PNB number of positive cores & $2.2 \pm 1.7$ & $3.3 \pm 2$ & 0.007 & 0.289 \\
\hline PNB tumor percentage & $22.4 \pm 23.6$ & $52.7 \pm 30.5$ & $<0.001$ & 0.004 \\
\hline RRP GS & $6.6 \pm 0.5$ & $7.5 \pm 0.9$ & $<0.001$ & 0.015 \\
\hline Tertiary Gleason pattern & $4.5 \pm 0.5$ & $4.9 \pm 0.3$ & 0.045 & - \\
\hline Tumor volume (cc) & $1.4 \pm 1.7$ & $3.8 \pm 4.3$ & 0.001 & 0.02 \\
\hline Surgical margin positivity, n (\%) & $6(12.2)$ & $13(40.6)$ & 0.003 & 0.067 \\
\hline Lymph node positivity, n (\%) & $0(0)$ & $3(9.4)$ & 0.016 & - \\
\hline Biochemical recurrence, n (\%) & $3(6.1)$ & $10(31.2)$ & 0.002 & 0.074 \\
\hline Recurrence-free survival (months) & $99.2 \pm 5.8$ & $77 \pm 12.1$ & 0.02 & - \\
\hline
\end{tabular}

higher RRP T stage, GS, and lymph node positivity in the 30 patients with TTE $<300 \mathrm{ng} / \mathrm{dL}$ compared to the 51 patients with TTE $>300 \mathrm{ng} / \mathrm{dL}$, while biochemical recurrence rates and recurrencefree survival times were similar between the groups. In a study conducted in China, it was reported that a TTE value of $<300 \mathrm{ng} /$ $\mathrm{dL}$ is nonprognostic, while a value of $<250 \mathrm{ng} / \mathrm{dL}$ is associated with high GS (23). This finding also demonstrates that the prognostic value of TTE may vary according to race. Considering the published studies overall, it can be said that a low pre-treatment TTE level is associated with a high post-treatment GS and pathological T stage. In studies of other hormones, FSH levels in a study including 96 patients were $11.57 \mathrm{IU} / \mathrm{L}$ and $23.67 \mathrm{IU} / \mathrm{L}$ in T2 and T3 patients, respectively, and FSH elevation in T3 patients was found to be significant (8). In another study, it was reported that low TTE correlated with high FSH and that both were associated with high-grade tumors (24). A study assessing EST level reported no significant correlation between EST and locally advanced PCa (25). However, our previous EST analysis in a locally advanced PCa
(T3a and $\mathrm{T} 3 \mathrm{~b}$ ) group revealed significant correlation between EST and T3b disease (9). It has been shown that LH level is not a significant factor in the prognosis of PCa (9). In the present study, we found that hormonal parameters other than TTE, especially FSH and EST levels, were not associated with pathological T stage. However, considering the results obtained in other studies, further research focusing on locally invasive PCa is warranted.

\section{Study Limitations}

The main limitations of our study are the retrospective data collection and low number of patients. Another important limitation is that since fTE, EST, LH, and FSH data were not available in all cases, the statistical analyses did not encompass all the patients and was conducted only among patients with available data (the number of patients whose records included these data and their distribution between the groups are presented in the tables). Nevertheless, we believe that the value of the available data and the similar patient numbers in the groups are important for the study. 
Çelik et al.

Effect of Hormonal Data on Prostate Cancer

\begin{tabular}{|c|c|c|c|c|}
\hline \multicolumn{2}{|l|}{ Mean values } & TTE $<300$ ng/dL $(n=30)$ & TTE $>300$ ng/dL $(n=51)$ & $p$ value \\
\hline \multicolumn{2}{|l|}{ Age (years) } & $63.2 \pm 6.6$ & $62.6 \pm 5.7$ & 0.618 \\
\hline \multicolumn{2}{|l|}{ PSA (ng/mL) } & $9.6 \pm 7.1$ & $7.5 \pm 5.3$ & 0.148 \\
\hline \multicolumn{2}{|l|}{ fPSA (ng/mL) } & $1.1 \pm 0.6$ & $1.2 \pm 1.2$ & 0.436 \\
\hline \multicolumn{2}{|l|}{ PV (cc) } & $49.9 \pm 28.2$ & $39.4 \pm 15.2$ & 0.056 \\
\hline \multicolumn{2}{|l|}{ PSA/PV (PSA density) (cc/ng/mL) } & $0.22 \pm 0.2$ & $0.22 \pm 0.18$ & 0.822 \\
\hline \multicolumn{2}{|l|}{ fPSA/PSA ratio } & $0.19 \pm 0.12$ & $0.17 \pm 0.11$ & 0.635 \\
\hline \multicolumn{2}{|l|}{ TTE (ng/dL) } & $212.5 \pm 67.2$ & $449.4 \pm 125.4$ & $<0.001$ \\
\hline \multicolumn{2}{|l|}{ fTE $(n g / d L)(n=73)$} & $9.2 \pm 9.2(n=27)$ & $12.2 \pm 11.3(n=46)$ & 0.004 \\
\hline \multicolumn{2}{|l|}{ TTE/PV (TTE density) } & $5.1 \pm 2.8$ & $13.7 \pm 8.2$ & $<0.001$ \\
\hline \multicolumn{2}{|l|}{ fTE/TTE ratio $(n=73)$} & $0.05 \pm 0.07(n=27)$ & $0.03 \pm 0.03(n=46)$ & 0.002 \\
\hline \multicolumn{2}{|l|}{ LH (IU/L) (n=57) } & $5.6 \pm 2.7(n=24)$ & $4.2 \pm 1.9(n=33)$ & 0.075 \\
\hline \multicolumn{2}{|l|}{$\mathrm{FSH}(\mathrm{IU} / \mathrm{L})(\mathrm{n}=59)$} & $10.1 \pm 7.8(n=25)$ & $8.7 \pm 9.6(n=34)$ & 0.312 \\
\hline \multicolumn{2}{|l|}{ EST $(p g / m L)(n=57)$} & $30.1 \pm 11.7(n=24)$ & $33 \pm 16.4(n=33)$ & 0.937 \\
\hline \multicolumn{2}{|l|}{ TTE/LH ratio $(n=57)$} & $43.2 \pm 25.9(n=24)$ & $118.6 \pm 57.7(n=33)$ & $<0.001$ \\
\hline \multicolumn{2}{|l|}{$\mathrm{FSH} / \mathrm{LH}$ ratio $(\mathrm{n}=57)$} & $1.7 \pm 0.7(n=24)$ & $2 \pm 1.3(n=33)$ & 0.649 \\
\hline \multicolumn{2}{|l|}{ TTE/FSH ratio $(n=59)$} & $30.5 \pm 25.5(n=25)$ & $76.3 \pm 48.7(n=34)$ & $<0.001$ \\
\hline \multirow[t]{3}{*}{ Clinical grade (rectal examination), n (\%) } & T1c-T2a & $24(80)$ & $48(94.1)$ & \multirow[t]{3}{*}{0.134} \\
\hline & $\mathrm{T} 2 \mathrm{~b}$ & $3(10)$ & $2(3.9)$ & \\
\hline & $\geq \mathrm{T} 2 \mathrm{c}$ & $3(10)$ & $1(2)$ & \\
\hline \multicolumn{2}{|l|}{ PNB GS } & $6.8 \pm 0.7$ & $6.6 \pm 0.6$ & 0.087 \\
\hline \multicolumn{2}{|l|}{ PNB PNI, n (\%) } & $12(40)$ & $13(25.5)$ & 0.172 \\
\hline \multicolumn{2}{|l|}{ PNB number of positive cores } & $2.7 \pm 1.9$ & $2.6 \pm 1.9$ & 0.615 \\
\hline \multicolumn{2}{|l|}{ PNB tumor percentage } & $41.2 \pm 32.3$ & $30.4 \pm 28.6$ & 0.133 \\
\hline \multirow[t]{3}{*}{$\mathrm{D}^{\prime}$ Amico risk classification, $\mathrm{n}(\%)$} & Low-risk & $6(20)$ & $22(43.1)$ & \multirow[t]{3}{*}{0.059} \\
\hline & Moderate-risk & $19(63.3)$ & $26(51)$ & \\
\hline & High-risk & $5(16.7)$ & $3(5.9)$ & \\
\hline
\end{tabular}

Table 3. Comparison of the clinical data and retropubic radical prostatectomy pathology results of patients with total testosterone $<300$ ng/ $\mathrm{dL}$ and total testosterone $>\mathbf{3 0 0} \mathrm{ng} / \mathrm{dL}$

\begin{tabular}{|c|c|c|c|c|}
\hline \multicolumn{2}{|l|}{ Mean values } & TTE $<300$ ng/dL $(n=30)$ & TTE $>300$ ng/dL $(n=51)$ & $\mathrm{p}$ value \\
\hline \multirow[t]{2}{*}{ RRP pathological T stage, n (\%) } & pT2 & $13(43.3)$ & $36(70.6)$ & \multirow[t]{2}{*}{0.015} \\
\hline & pT3 & $17(56.7)$ & $15(29.4)$ & \\
\hline \multirow[t]{2}{*}{ Locally invasive T stage, n (\%) } & рT3a & $14(82.4)$ & $10(66.7)$ & \multirow[t]{2}{*}{0.306} \\
\hline & pT3b & $3(17.6)$ & $5(33.3)$ & \\
\hline \multicolumn{2}{|l|}{ RRP GS } & $7.3 \pm 0.9$ & $6.8 \pm 0.7$ & 0.013 \\
\hline \multicolumn{2}{|l|}{ RRP tertiary Gleason pattern } & $4.9 \pm 0.3$ & $4.6 \pm 0.5$ & 0.2 \\
\hline \multicolumn{2}{|l|}{ Lymph node positivity, n (\%) } & $3(10)$ & $0(0)$ & 0.021 \\
\hline \multicolumn{2}{|l|}{ Surgical margin positivity, n (\%) } & $9(30)$ & $10(19.6)$ & 0.286 \\
\hline \multicolumn{2}{|l|}{ Tumor volume (cc) } & $2.3 \pm 2.9$ & $2.3 \pm 3.4$ & 0.607 \\
\hline \multicolumn{2}{|l|}{ Grade increase, n (\%) } & $15(50)$ & $18(35.3)$ & 0.193 \\
\hline \multicolumn{2}{|l|}{ Stage increase, $\mathrm{n}(\%)$} & $14(46.7)$ & $14(27.5)$ & 0.079 \\
\hline \multicolumn{2}{|l|}{ Biochemical recurrence, n (\%) } & $6(20)$ & $9(17.6)$ & 0.792 \\
\hline \multicolumn{2}{|l|}{ Recurrence-free survival (months) } & $87.7 \pm 13.8$ & $91.3 \pm 6.4$ & 0.571 \\
\hline
\end{tabular}




\section{Conclusion}

We showed in this study that low TTE and low TTE density detected in pre-PNB hormone tests are associated with postRRP locally invasive PCa. In particular, TTE value $<30 \mathrm{ng} / \mathrm{dL}$ was associated with higher pathological $T$ stage, GS, and lymph node positivity, but low TTE level did not have an effect on biochemical recurrence or recurrence-free survival. Prospective cohort studies with large patient numbers are needed to clarify TTE results and the effects of FSH and EST levels on PCa.

\section{Ethics}

Ethics Committee Approval: Retrospective study.

Informed Consent: Retrospective study.

Peer-review: Externally peer-reviewed.

\section{Authorship Contributions}

Surgical and Medical Practices: S.Ç., O.B., Ö.D., G.A., Concept: S.Ç., Design: S.Ç., O.B., Data Collection or Processing: S.Ç., H.A.Y., B.T., K.Y., Analysis or Interpretation: S.Ç., O.B., Ö.D., K.Y., G.A., Literature Search: S.Ç., O.B., H.A.Y., Writing: S.Ç.

Conflict of Interest: No conflict of interest was declared by the authors.

Financial Disclosure: The authors declared that this study received no financial support.

\section{References}

1. Partin AW, Kattan MW, Subong EN, et al. Combination of prostate specific antigen, clinical stage, and Gleason score to predict pathological stage of localized prostate cancer. A multi-institutional update. JAMA 1997;277:1445-1451.

2. Huland H, Hammerer P, Henke RP, Huland E. Preoperative prediction of tumor heterogeneity and recurrence after radical prostatectomy for localized prostatic carcinoma with digital rectal, examination prostate specific antigen and the results of 6 systematic biopsies. J Urol 1996;155:1344-1347.

3. Peller PA, Young DC, Marmaduke DP, et al. Sextant prostate biopsies. A histopathologic correlation with radical prostatectomy specimens. Cancer 1995; 75:530-538.

4. Bozkurt O, Çelik S, Demir Ö, et al. Clinical significance of perineural invasion in prostate needle biopsy in patients diagnosed with extraprostatic extension and seminal vesicle invasion after radical prostatectomy. Bull Urooncol 2015; 14:5-7.

5. Ongun S, Celik S, Gul-Niflioglu G, et al. Are active surveillance criteria sufficient for predicting advanced stage prostate cancer patients? Actas Urol Esp 2014;38:499-505.

6. DeLancey JO, Wood DP Jr, He C, et al. Evidence of perineural invasion on prostate biopsy specimen and survival after radical prostatectomy. Urology 2013;81:354-357.

7. Ross PL, Scardino PT, Kattan MW. A catalog of prostate cancer nomograms. J Urol 2001;165:1562-1568.

8. Ide H, Terado Y, Sakamaki K, et al. Serum level of follicle-stimulating hormone is associated with extraprostatic extension of prostate cancer. Prostate Int 2013;1:109-112.
9. Çelik S, Bozkurt O, Yıldız HA, et al. Association between hormonal evaluation before prostate needle biopsy and locally advanced prostate cancer. Bull Urooncol 2016;15:52-56.

10. Çelik S, Bozkurt O, Yıldız HA, et al. Significance of pretreatment testosterone levels in prostate cancer risk groups. Bull Urooncol 2016;15:98-102.

11. Huggins C, Stevens RE, Hodges CV. Studies on prostatic cancer: II. The effects of castration on advanced carcinoma of the prostate gland. Arch Surg 1941;43:209.

12. Chodak GW, Vogelzang NJ, Caplan RJ, et al. Independent prognostic factors in patients with metastatic (stage D2) prostate cancer. The Zoladex Study Group. JAMA 1991;265:618-621.

13. Chen SS, Chen KK, Lin AT, et al. The correlation between pretreatment serum hormone levels and treatment outcome for patients with prostatic cancer and bony metastasis. BJU Int 2002;89:710-713.

14. Iversen P, Rasmussen F, Christensen IJ. Serum testosterone as a prognostic factor in patients with advanced prostatic carcinoma. Scand J Urol Nephrol 1994;157:41-47.

15. Miller LR, Partin AW, Chan DW, et al. Influence of radical prostatectomy on serum hormone levels. J Urol 1998;160:449-453.

16. Teloken C, Da Ros CT, Caraver F, et al. Low serum testosterone levels are associated with positive surgical margins in radical retropubic prostatectomy: hypogonadism represents bad prognosisin prostate cancer. J Urol 2005; 174:2178-2180.

17. Isom-Batz G, Bianco FJ Jr, Kattan MW, et al. Testosterone as a predictor of pathological stage in clinically localized prostate cancer. j Urol 2005;173:1935-1937.

18. Gao $Y$, Jiang $C Y$, Mao SK, et al. Low serum testosterone predicts upgrading and upstaging of prostate cancer after radical prostatectomy. Asian J Androl 2016;18:639-643.

19. Pichon A, Neuzillet $Y$, Botto $H$, et al. Preoperative low serum testosterone is associated with high-grade prostate cancer and an increased Gleason score upgrading. Prostate Cancer Prostatic Dis 2015;18:382-387.

20. Imamotoa T, Suzukia H, Fukasawa $S$, et al. Pretreatment serum testosterone level as a predictive factor of pathological stage in localized prostate cancer patients treated with radical prostatectomy. Eur Urol 2005;47:308-312.

21. Xylinas E, Ploussard G, Durand $X$, et al. Low pretreatment total testosterone $(<3 \mathrm{ng} / \mathrm{mL})$ predicts extraprostatic disease in prostatectomy specimens from patients with preoperative localized prostate cancer. BJU Int 2010;107:1400-1403.

22. Park J, Cho SY, Jeong SH, et al. Low testosterone level is an independent risk factor for high-grade prostate cancer detection at biopsy. BJU Int 2016;118:230-235.

23. Dai B, Qu Y, Kong Y, et al. Low pretreatment serum total testosterone is associated with a high incidence of Gleason score 8-10 disease in prostatectomy specimens: data from ethnic Chinese patients with localized prostate cancer. BJU Int 2012;110:667-672.

24. Porcaro AB, Siracusano S, Luyk N, et al. Simultaneous Measurements of Follicle Stimulating Hormone and Total Testosterone and Associations in Clinically Localized Prostate Cancer. Curr Urol 2016;10:174-181.

25. Schnoeller TJ, Steinestel J, Zengerling F, et al. Serum 17 $\beta$-estradiol fails as a marker in identification of aggressive tumour disease in patients with localized prostate cancer. World J Urol 2015;33:1979-1984. 